\title{
Dithiocarbamate Self-Assembled Monolayers as Efficient Surface Modifiers for Low Work Function Noble Metals
}

Dominik Meyer ${ }^{*, 1}$, Tobias Schäfer ${ }^{1}$, Philip Schulz ${ }^{1,2,3}$, Sebastian Jung ${ }^{1}$, Daniel Mokros ${ }^{1}$, Ingolf Segger $^{1}$, Julia Rittich ${ }^{1}$, Franziska Maercks ${ }^{1}$, Christian Effertz ${ }^{1}$, Riccardo Mazzarello ${ }^{4,5}$, Matthias Wuttig* ${ }^{1,5}$

${ }^{1}$ I. Institute of Physics (IA), RWTH Aachen University, 52056 Aachen, Germany

${ }^{2}$ Department of Electrical Engineering, Princeton University, Princeton, NJ 08544, USA

${ }^{3}$ National Center for Photovoltaics, National Renewable Energy Laboratory, Golden CO, 80401, USA

${ }^{4}$ Institute for Theoretical Solid State Physics, RWTH Aachen University, 52056 Aachen, Germany

5 JARA-Fundamentals of Future Information Technology, RWTH Aachen University, 52056 Aachen, Germany 


\section{SUPPORTING INFORMATTION}

Appendix A: Computational and Experimental Details

Figure S1: Initial surface slabs (top view) for the DFT simulations of C2DTC on noble metals using the ultra-soft Vanderbilt pseudo potentials and gradient-corrected PBE functionals. ${ }^{1,2}$ Kinetic energy cutoffs for the wave functions and densities were set to 30 Ry and $300 \mathrm{Ry}$, respectively. An 8x8x1 Monkhorst-Pack grid has been used for k-point integration of the small 2x3 cells, and 6x6x1 k-point meshes were employed for the larger cells.

For all metals, the $2 \times 3$ (dimer) cell produces a too high surface coverage, which results in instable monolayers due to a partial desorption of one molecule.

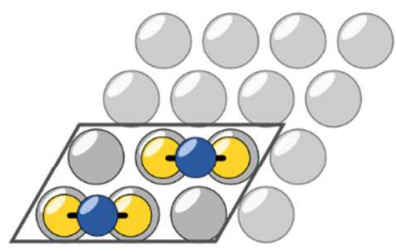

$2 \times 3$ (dimer)

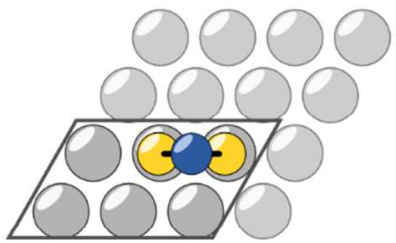

$2 \times 3$ (monomer)

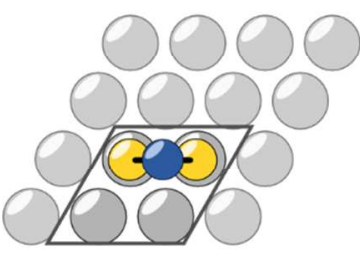

$2 \times 2$ (monomer)

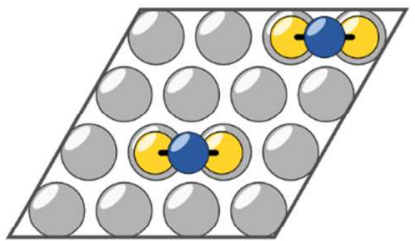

$4 \times 4$ (dimer)

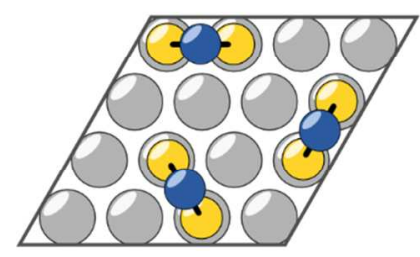

$4 \times 4$ (trimer)

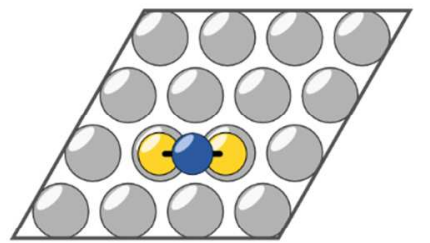

$4 \times 4$ (monomer) $\bigcirc \mathbf{s}$

○ $N$ metal 
Figure S2: Exemplary AFM images of untreated and DTC modified noble metals on mika substrates. For all samples, large plateaus with low surface roughness are observed. Although the modification alters the surface, no massive increase of the surface roughness nor monolayerinduced pitting is observed.

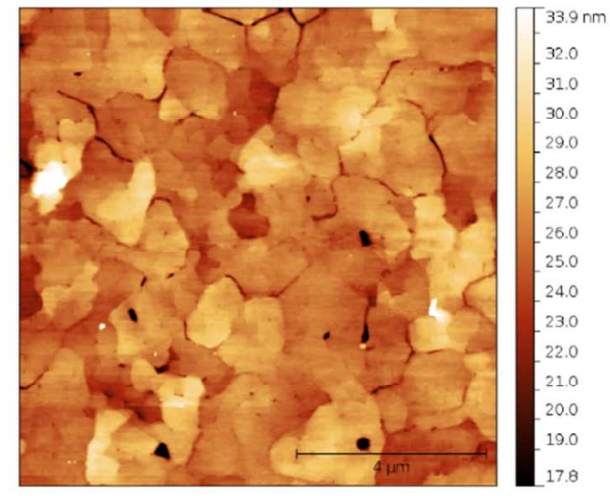

A: Au pure on mika RMS roughness $=1.98 \mathrm{~nm}$

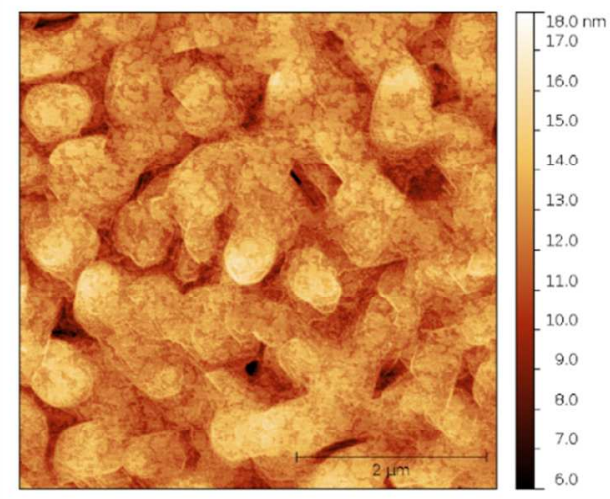

\section{C: Ag pure on mika} RMS roughness $=1.36 \mathrm{~nm}$

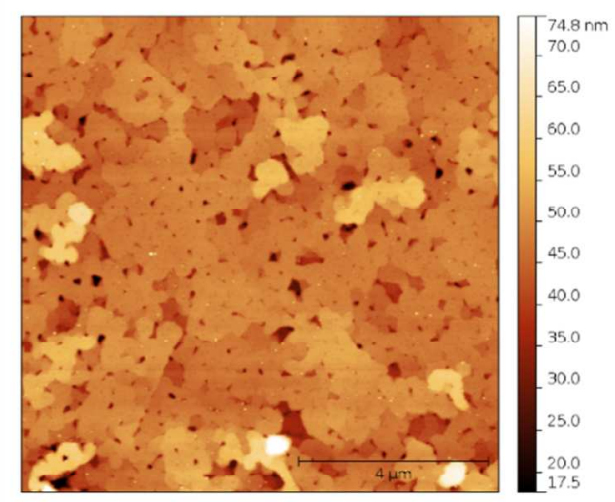

E: Cu pure on mika

$\mathrm{RMS}$ roughness $=4.88 \mathrm{~nm}$

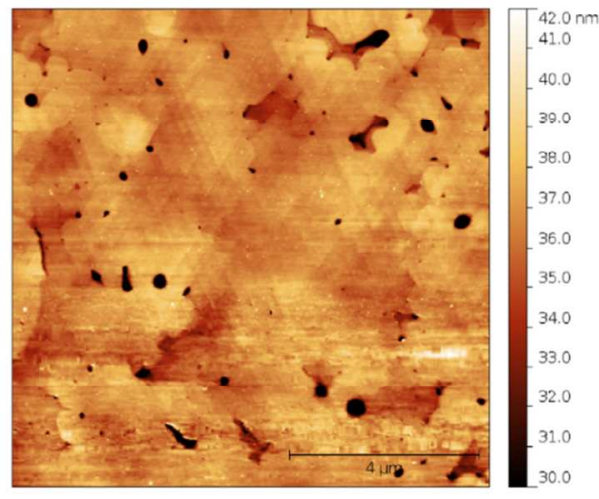

B: Au with DTC on mika RMS roughness $=1.79 \mathrm{~nm}$

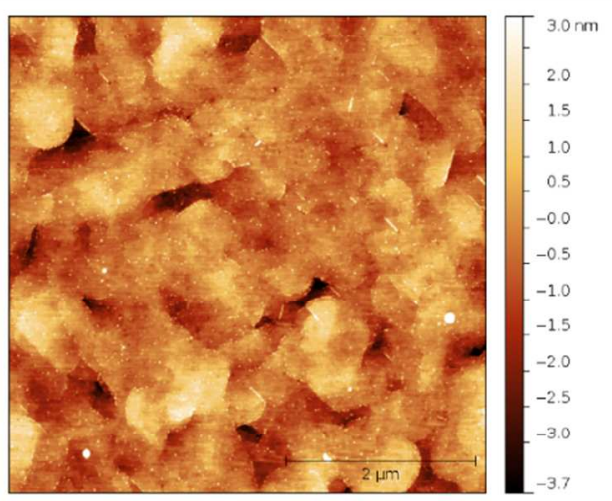

D: Ag with SAM on mika RMS roughness $=0.90 \mathrm{~nm}$

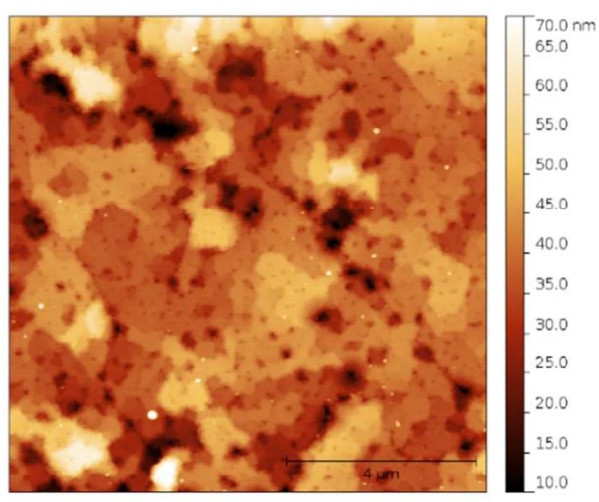

F: Cu with SAM on mika

RMS roughness $=8.28 \mathrm{~nm}$ 
Appendix B: XPS measurements of SAMs on silver and copper

Figure S3: N 1s core level of C2DTC on gold (A), silver (B) and copper (C). For all systems the nitrogen $1 \mathrm{~s}$ core level is located at a binding energy of $399.9 \mathrm{eV}$. A longer alkyl chain length substitution of the DTCs does not impact the position of this core level.
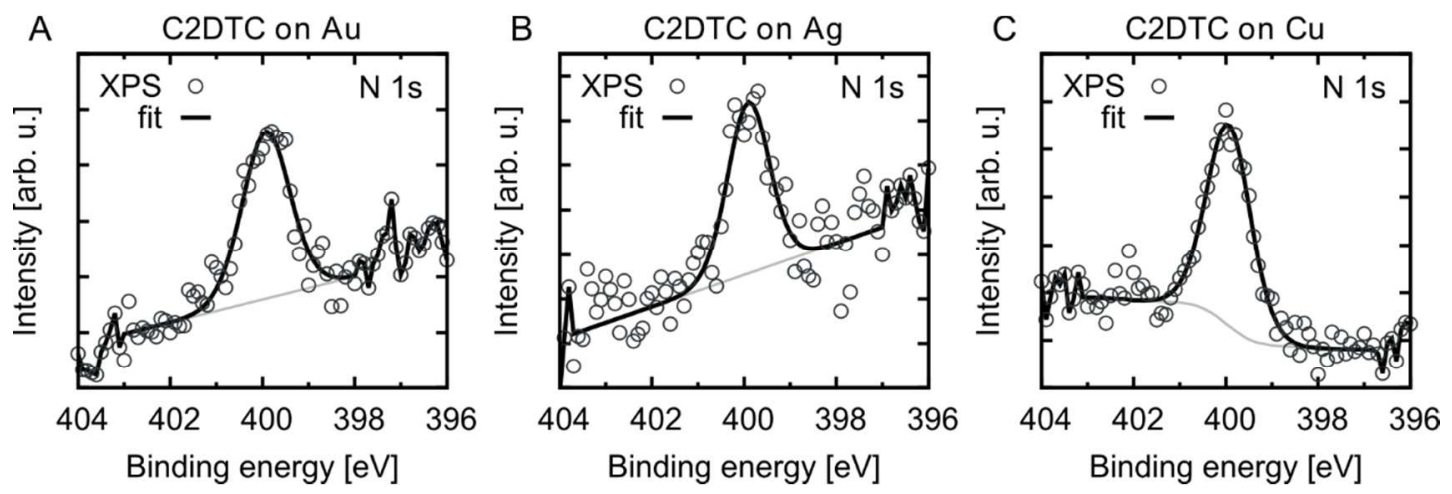
Figure S4: S 2p core level of DTC on silver (A-E) and copper (F-J). Component (i) always denotes the doublet with the higher binding energy compared to component (ii). On silver, $\mathrm{E}_{\mathrm{B}}\left(\mathrm{S} 2 \mathrm{p} 3 / 2\right.$ (i)) is centered at $161.8 \mathrm{eV}$ and $\mathrm{E}_{\mathrm{B}}(\mathrm{S} 2 \mathrm{p} 3 / 2$ (ii)) at $160.8 \mathrm{eV}$. On copper, $\mathrm{E}_{\mathrm{B}}(\mathrm{S} 2 \mathrm{p} 3 / 2(\mathrm{i}))$ is mainly located at $162.2 \mathrm{eV}$ and $\mathrm{E}_{\mathrm{B}}(\mathrm{S} 2 \mathrm{p} 3 / 2(\mathrm{ii}))$ at $161.5 \mathrm{eV}$.
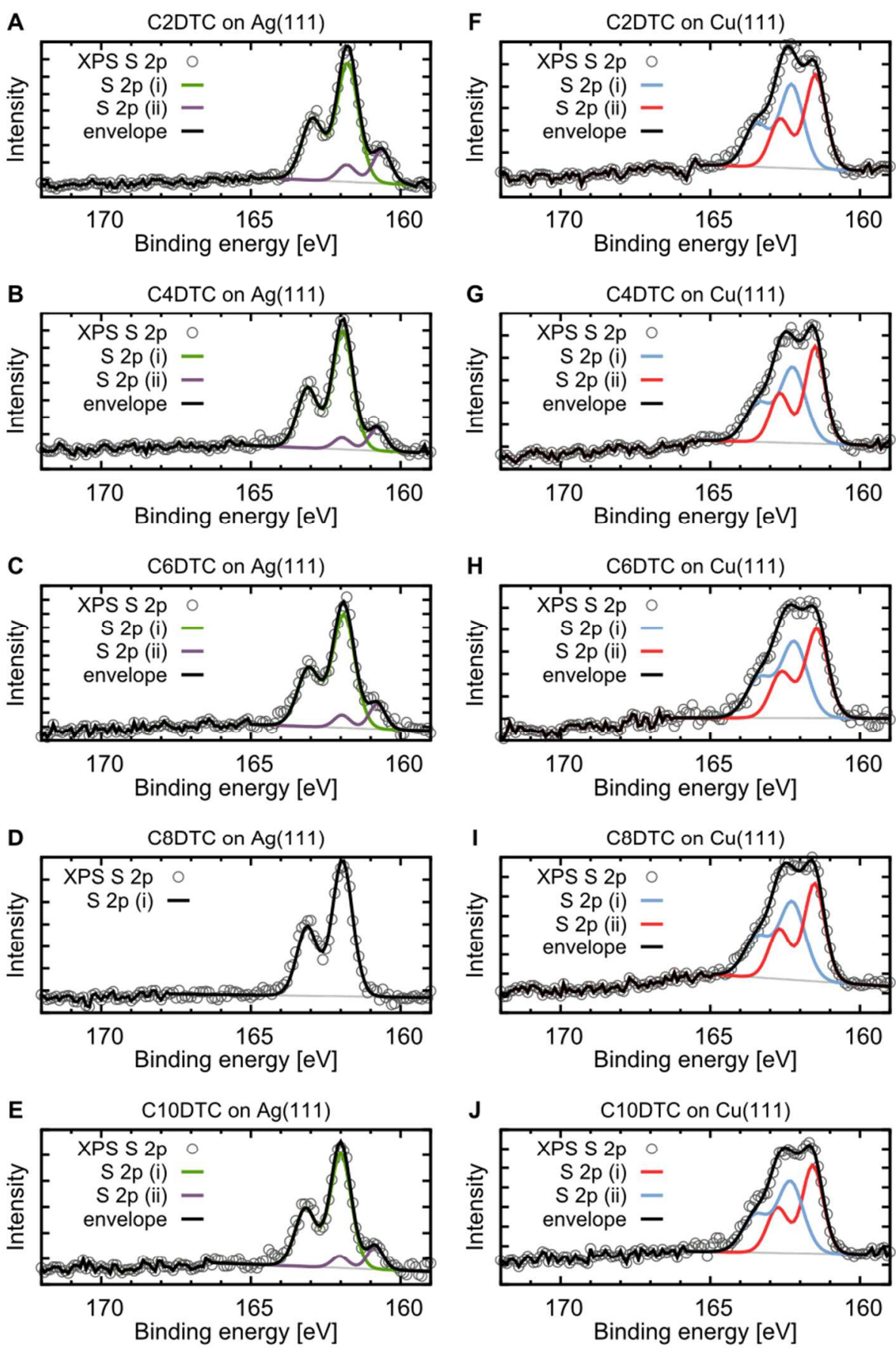
Table S1: Results of surface coverage for all monolayers on silver. Molecular surface densities on $\operatorname{Ag}(111)$ are extracted from the area intensity of the $S 2 p$ core level peak. Values for the surface coverage of DTC SAMs have determined after the methods of Schreiber and Bramblett. $^{3,4}$ The constant offset between the two models are attributed to the different methodology, as also discussed by Bramblett et al. ${ }^{4}$ Reasonable values for C10Thiol are found with both methods compared to the theoretical value discussed by Ulman.,

\begin{tabular}{|l|l|l|l|l|l|l|}
\hline \multicolumn{2}{|l|}{ surface coverage of molecules on $\mathrm{Ag}(111)$ in $10^{14} \mathrm{~cm}^{-2}$} \\
\hline & C2DTC & C4DTC & C6DTC & C8DTC & C10DTC & C10Thiol \\
\hline Schreiber: S/Ag & 2.0 & 1.5 & 1.7 & 1.4 & 1.8 & 4.1 \\
\hline Bramblett: S/Ag & 2.2 & 1.7 & 1.9 & 1.6 & 1.9 & 3.9 \\
\hline
\end{tabular}

Table S2: Results of surface coverage for all monolayers on copper. On $\mathrm{Cu}(111)$. An unrealistic density of DTC molecules is derived from the $\mathrm{S} / \mathrm{Cu}$ ratio since a large amount of sulfur and carbon is detected. This finding indicates that residues of non-reacted CS2 are incorporated in the DTC SAM on copper. Hence, the evaluation of the N 1s core level peak is chosen to extract the surface densities of DTC molecules according to the report of Bramblett. ${ }^{4}$ Surface densities found for C10Thiol agree with comparable monolayers on copper analyzed using STM. ${ }^{6-8}$

\begin{tabular}{|l|l|l|l|l|l|l|}
\hline \multicolumn{2}{|l|}{ surface coverage of molecules on $\mathrm{Cu}(111)$ in $10^{14} \mathrm{~cm}^{-2}$} \\
& C2DTC & C4DTC & C6DTC & C8DTC & C10DTC & C10Thiol \\
\hline Bramblett: $\mathrm{N} / \mathrm{Cu}$ & 1.5 & 1.3 & 1.6 & 1.4 & 1.3 & --- \\
\hline Bramblett: $\mathrm{S} / \mathrm{Cu}$ & 4.7 & 4.1 & 4.0 & 3.5 & 3.3 & 6.8 \\
\hline Schreiber: $\mathrm{S} / \mathrm{Cu}$ & 4.3 & 4.1 & 4.1 & 3.6 & 3.5 & 5.1 \\
\hline
\end{tabular}


Appendix C: Binding of DTC molecules with metal surfaces

Figure S5: Projected DOS of frontier S 3p states with metal d-states from DFT calculation of C2DTC on gold (A), silver (B) and copper (C). Molecular states and metal states with minor hybridization have been omitted for the sake of clarity. For each system, a predominating hybridization of the metal $\mathrm{dz}^{2}$ with sulfur $3 \mathrm{~d}$ states can be identified.
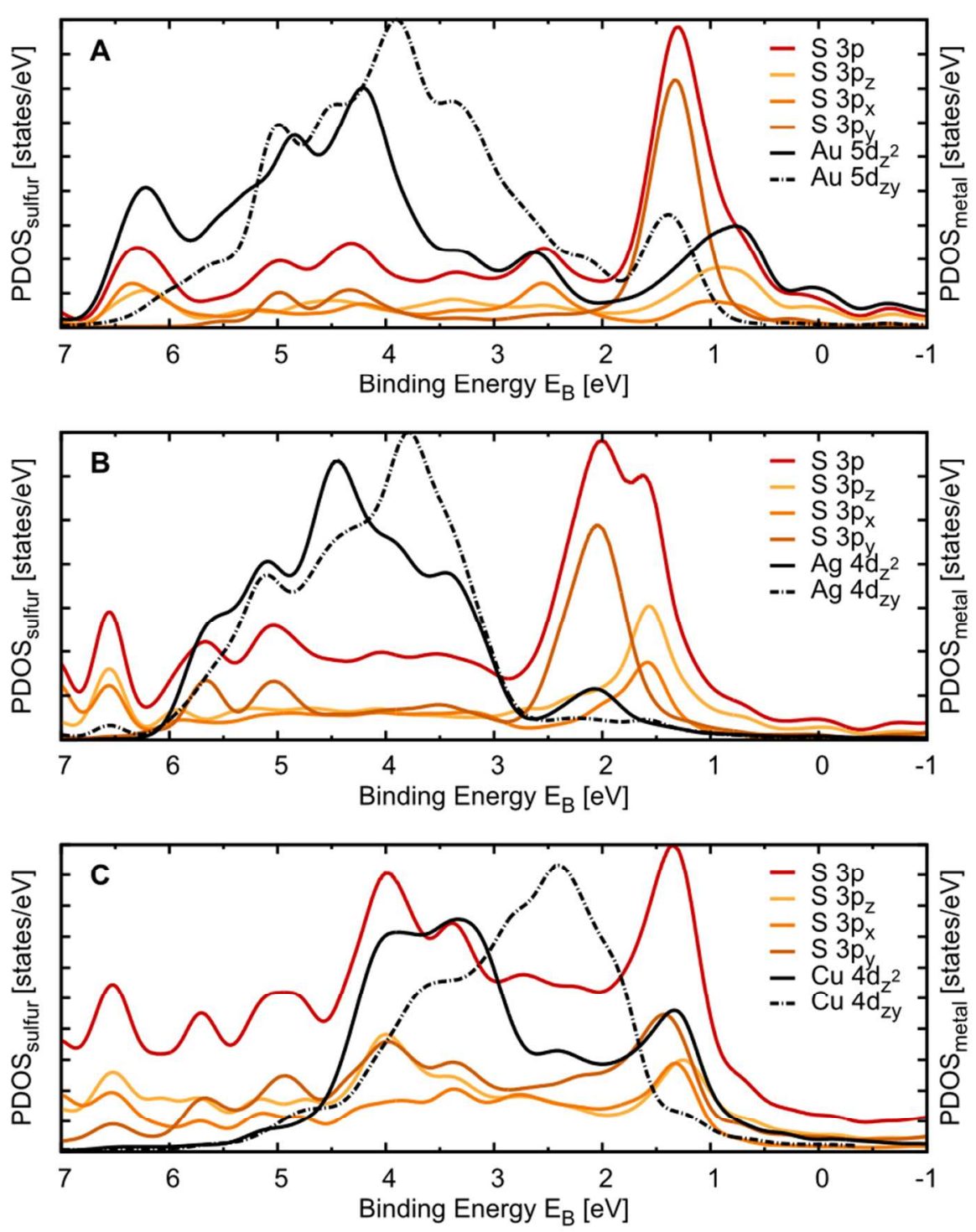
Appendix D: UPS results of investigated SAMs

Figure S6: UPS measurements of CnDTC monolayers on $\mathrm{Ag}(111)(\mathrm{A}$ and $\mathrm{B})$ and $\mathrm{Cu}(111)(\mathrm{C}$ and D). The Fermi edge is positioned at a binding energy of $0 \mathrm{eV}$. The graph illustrated in $\mathrm{B}$ and D are vertically offset for clarity. Secondary electron ionization cutoff (A and C) to determine the work function, extracted values listed in table S3.
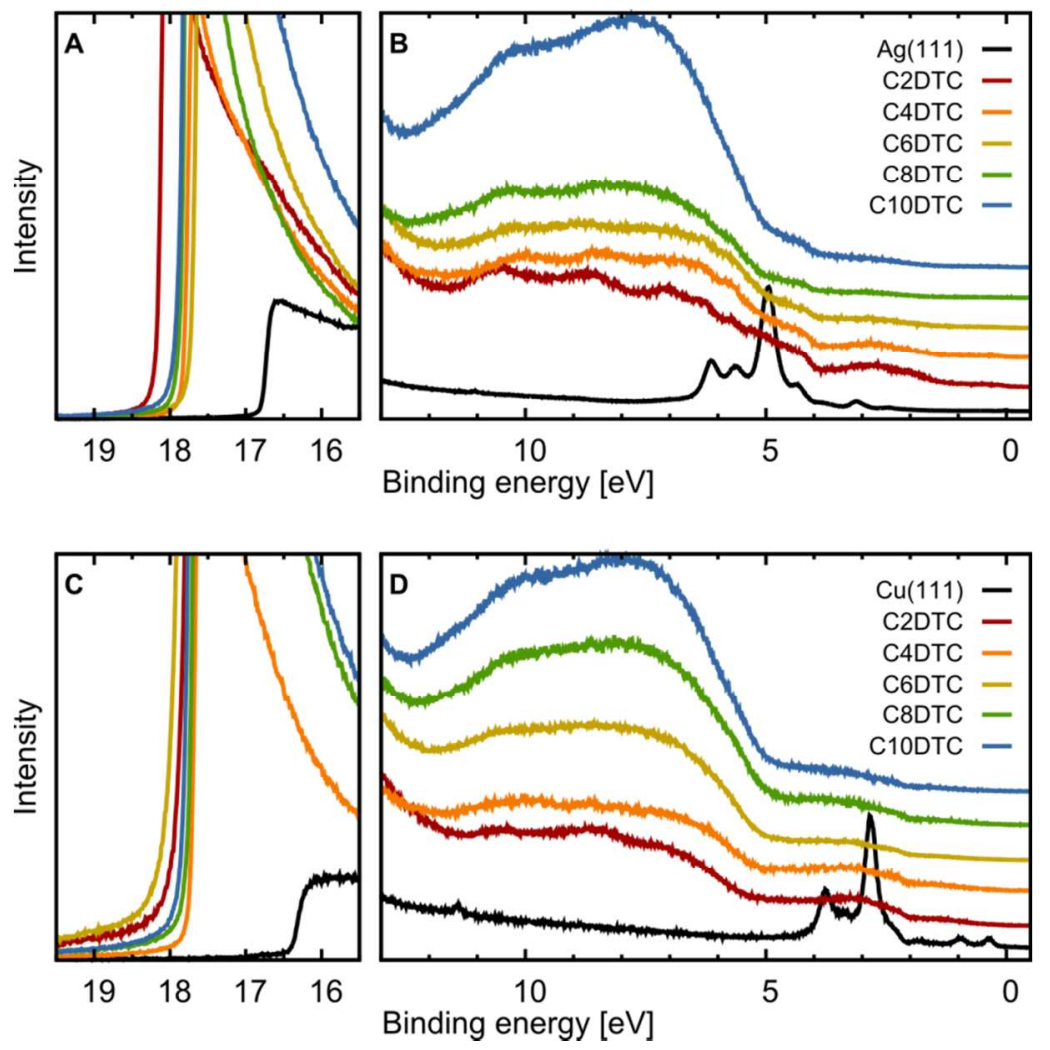
Figure S7: Work functions extracted from UPS measurements of CnDTC monolayers on $\mathrm{Ag}(111), \mathrm{Au}(111)$ and $\mathrm{Cu}(111)$ (A). A universal work function is achieved for all $\mathrm{CnDTC}$ modified metals. Odd and even CnDTC show similar work function changes for each metal surfaces (B). The work function values extracted are listed in table S3.
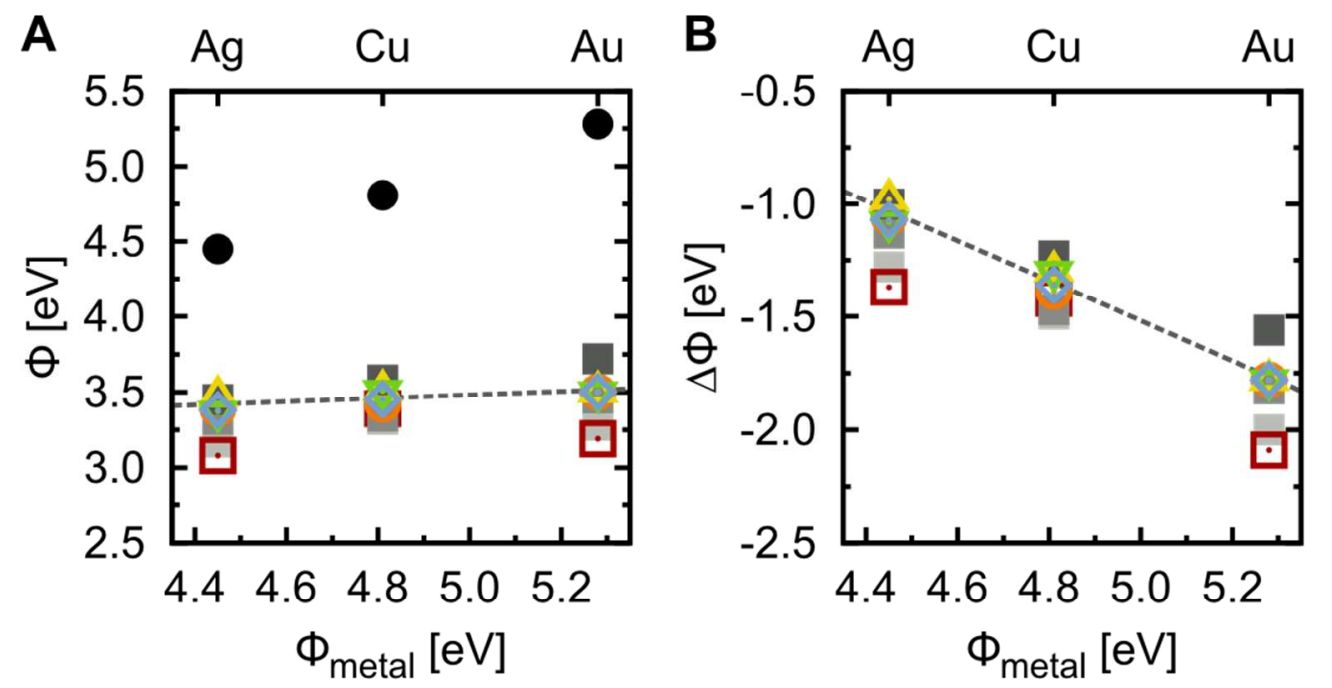

C1DTC
C2DTC $\square$
C3DTC
C4DTC $\odot$
C5DTC $\square$
C6DTC $\triangle$
C8DTC $\nabla$
C10DTC $\odot$
metals

$\Phi_{\text {metal }}[\mathrm{eV}]$ 
Table S3: Work functions $\Phi$ in eV from UPS measurements. Work function of clean metals with highly textured (111) orientation are in good agreement with literature values. ${ }^{9}$ *Values for CnDTC on gold previously reported by Schulz and coworkers. ${ }^{10}$ All values are given with a statistical error of $<0.1 \mathrm{eV}$ due to sample preparation, monolayer quality and resolution.

\begin{tabular}{|c|c|c|c|c|c|c|c|c|c|c|}
\hline $\begin{array}{c}\Phi \text { in } \\
\text { eV }\end{array}$ & $\begin{array}{c}\text { Plain } \\
\text { metal }\end{array}$ & $\begin{array}{c}\text { C1 } \\
\text { DTC }\end{array}$ & $\begin{array}{c}\text { C2 } \\
\text { DTC }\end{array}$ & $\begin{array}{c}\text { C3 } \\
\text { DTC }\end{array}$ & $\begin{array}{c}\text { C4 } \\
\text { DTC }\end{array}$ & $\begin{array}{c}\text { C5 } \\
\text { DTC }\end{array}$ & $\begin{array}{c}\text { C6 } \\
\text { DTC }\end{array}$ & $\begin{array}{c}\text { C8 } \\
\text { DTC }\end{array}$ & $\begin{array}{c}\text { C10 } \\
\text { DTC }\end{array}$ & $\begin{array}{c}\text { C10 } \\
\text { Thiol }\end{array}$ \\
\hline Silver & 4.5 & 3.2 & 3.1 & 3.3 & 3.4 & 3.5 & 3.5 & 3.4 & 3.4 & 3.7 \\
\hline Copper & 4.8 & 3.3 & 3.4 & 3.3 & 3.4 & 3.6 & 3.5 & 3.5 & 3.5 & 3.7 \\
\hline Gold* & 5.3 & 3.3 & 3.2 & 3.5 & 3.5 & 3.7 & 3.5 & 3.5 & 3.5 & 4.1 \\
\hline
\end{tabular}


Figure S8: C 1s core level of C2DTC in comparison with those of decanethiol (C10Thiol) on the noble metals $\mathrm{Au}, \mathrm{Cu}$ and $\mathrm{Ag}$. The core level of the decanethiol SAMs is dominated by a single contribution of C-C and C-H bonds at $285.1 \mathrm{eV}$. This is also observed for every DTC layer (black lines). In addition, a coordination of C-N species can be identified at higher binding energies at $(286.0 \pm 0.2) \mathrm{eV}$ (blue lines). A low amount of impurities (here oxidized carbon C-O) are observed at $288.3 \mathrm{eV}$ (red line) and may result from residual ethanol molecules.
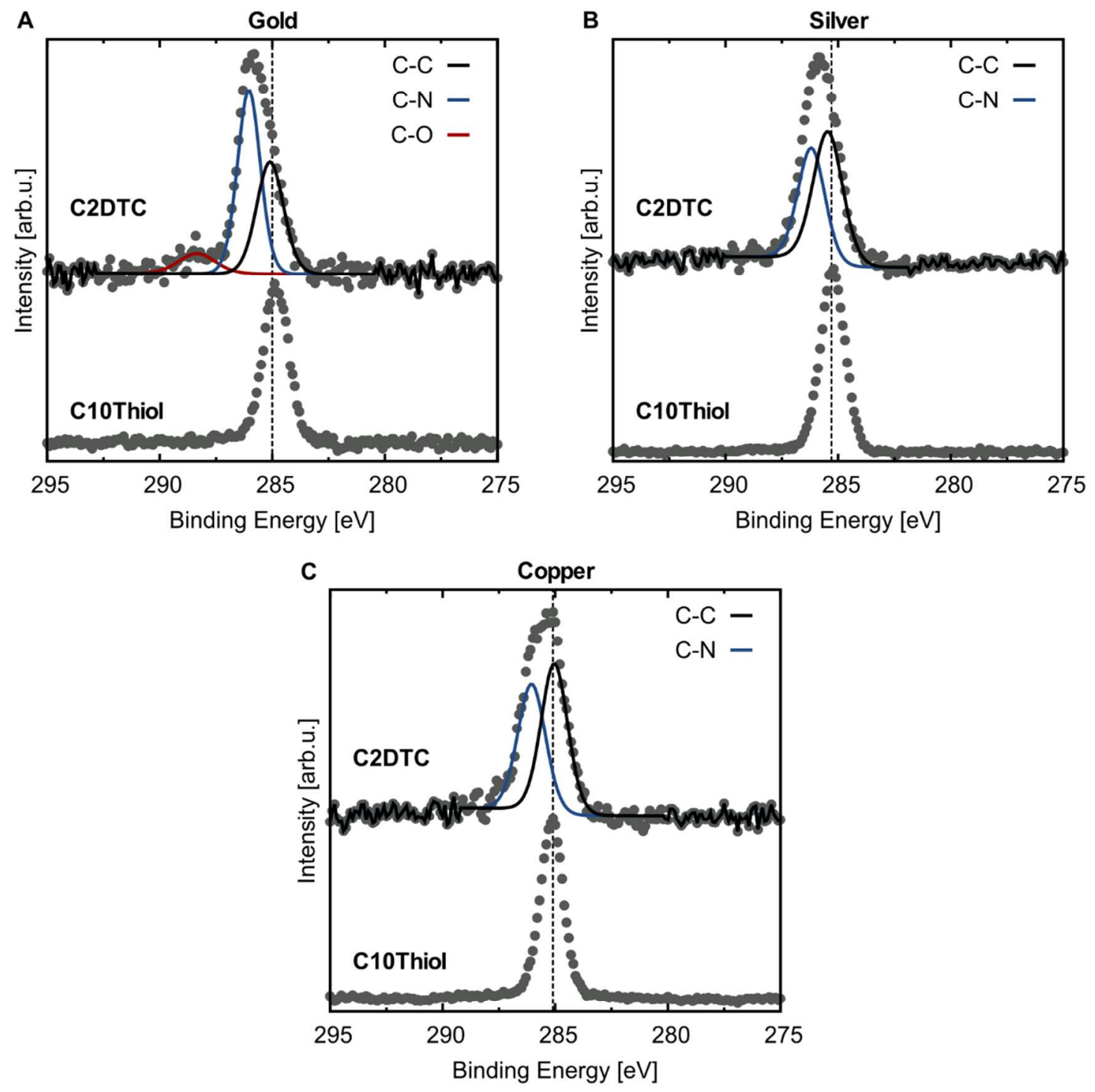
Appendix E: Comparison of interface dipoles between DTC and thiol

Figure S9: Interface dipole formation of diethyldithiocarbamate (C2DTC, top row) versus ethanethiol (C2Thiol, bottom row) on gold with equal surface coverage. The average bond dipole from DFT is equal at identic molecular density with $\mathrm{BD}_{\mathrm{C} 2 \mathrm{DTC}}=0.7 \mathrm{eV}$ and $\mathrm{BD}_{\mathrm{C} 2 \mathrm{Thiol}}=0.7 \mathrm{eV}$. However, the contribution from the intrinsic dipole of the molecular layers show as pronounced difference with $\Delta \mathrm{E}_{\mathrm{C} 2 \mathrm{DTC}}=1.3 \mathrm{eV}$ and $\Delta \mathrm{E}_{\mathrm{C} 2 \text { Thiol }}=0.3 \mathrm{eV}$.
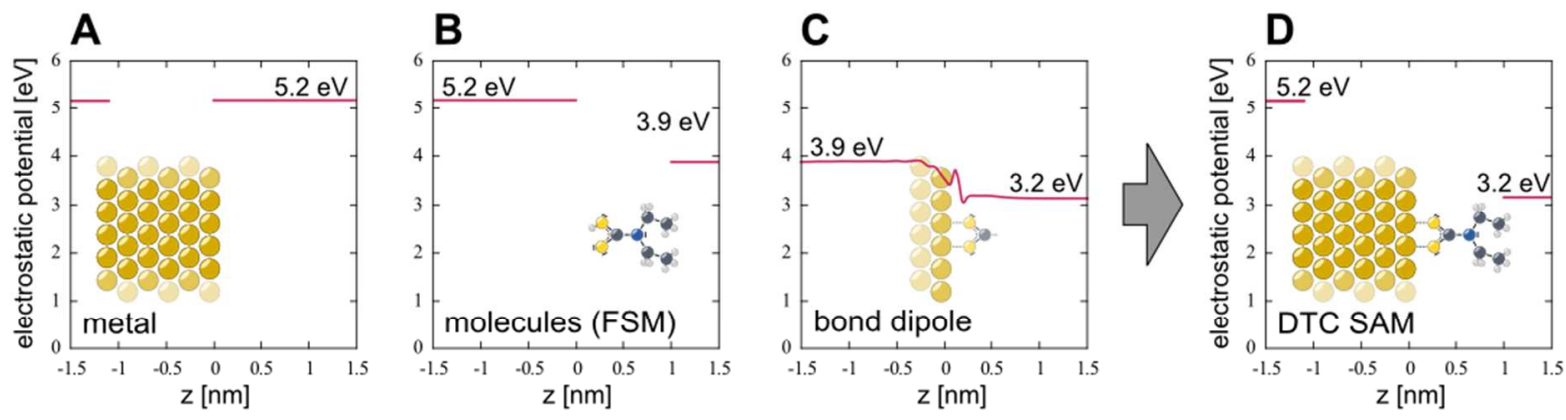

\section{C2DTC}
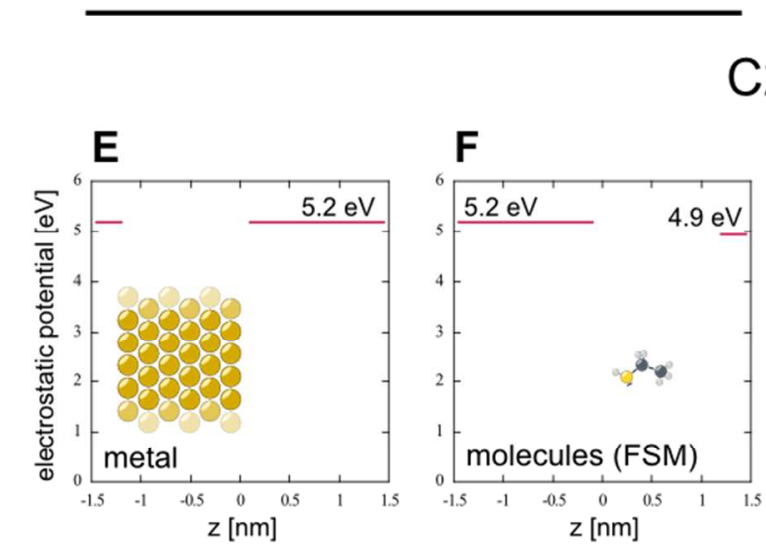

VS

C2Thiol
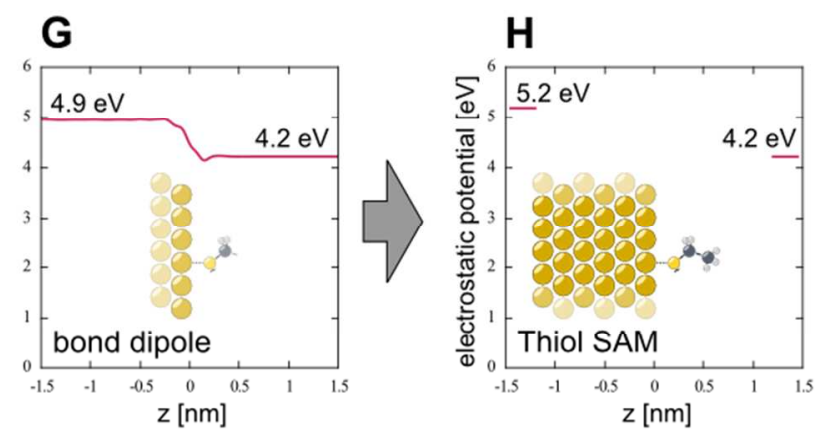
Appendix F: Additional results of PTCDI- $\mathrm{C}_{13}$ OTFTs with modified electrodes

Figure S10: (a) Transfer characteristic of PTCDI- $\mathrm{C}_{13}$ OTFTs with DTC covered copper S/Delectrodes. Mobilities and threshold voltages are given in table S4. (b) TLM plots to extract the contact resistance. Values around $2 \mathrm{M} \Omega \mathrm{cm}$ are observed, similar to the contact resistances of OTFTs with modified silver electrodes. Only C8DTC and C10DTC SAMs could successfully be implemented in OTFT devices. For C2-C6DTC the device preparation did not work with sufficient accuracy: During immersion the copper layers delaminated from the substrate surface, making it impossible to extract a reliable contact resistance. This problem of copper delamination explains the slight performance differences.
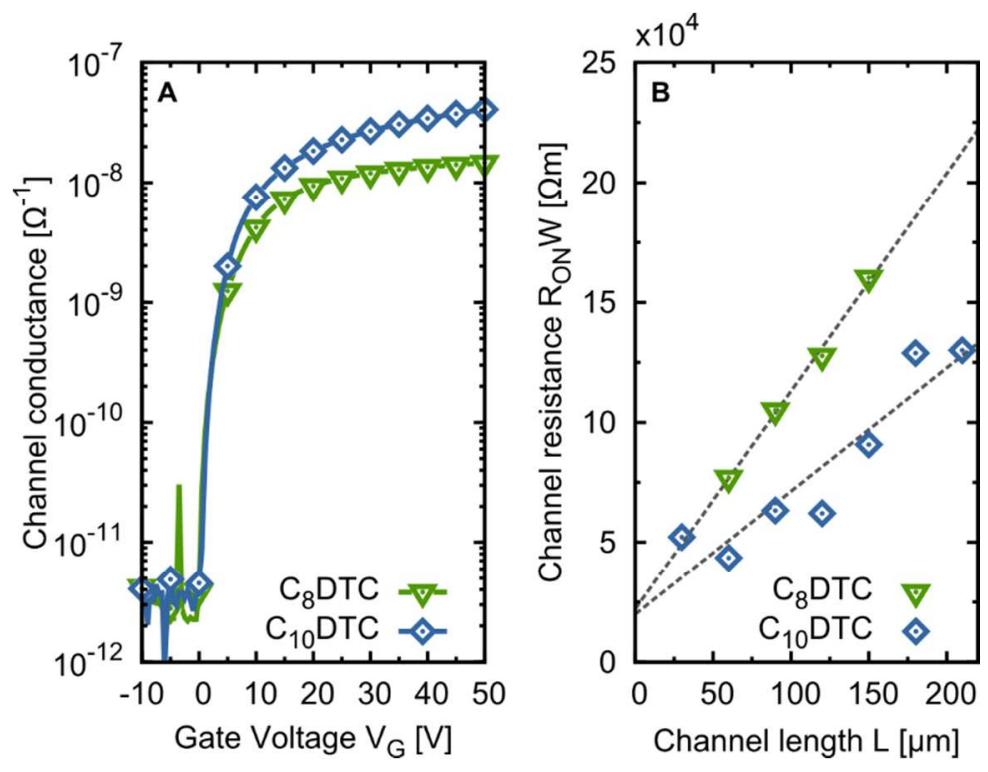
Figure S11: (a) Transfer characteristic of PTCDI-C ${ }_{13}$ OTFTs with C10DTC and C10Thiol covered silver S/D-electrodes. (b) TLM plots revealing almost equal contact resistances due to lower work function with respect to the LUMO of PTCDI-C13 for the two modifiers with equal alkyl chain length. C10 Thiol shows a slight better performance in Mobility and contact resistance due to an optimal energy level alignment. Even if the work function lies below the LUMO of the active organic material charge transfer occurs and another kind of energy barrier is created. This results in slight performance differences.
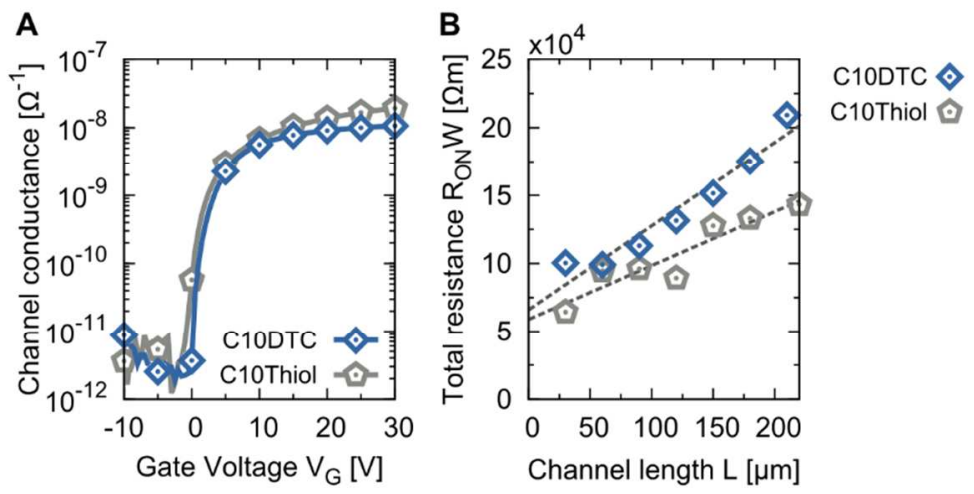
Table S4: Mobilities and threshold voltages of PTCDI-C13 OTFTs with Cn DTC modified silver S/D-electrodes and C8 DTC and C10 DTC modified copper S/D-electrodes.

Mobilities are extracted from TLM method at $\left|V_{G}-V_{t h}\right|=20 \mathrm{~V}$. $V_{t h, s a t}$ is the onset voltage for transistor switching and $V_{t h, l i n}$ is the onset of the linear regime of the transfer characteristic.

\begin{tabular}{|c|l|l|l|l|l|l|l|}
\hline \multirow{2}{*}{ PTCDI-C13 OTFT } & \multicolumn{5}{|c|}{ Silver S/D-electrodes } & \multicolumn{2}{c|}{ Copper S/D-electrodes } \\
\hline Modification & C4 DTC & C6 DTC & C8 DTC & C10 DTC & C10 Thiol & C8 DTC & C10 DTC \\
\hline Mobility $\mu$ in $\frac{\mathrm{cm}^{2}}{V s}$ & $\begin{array}{l}0.011 \\
\pm 0.001\end{array}$ & $\begin{array}{l}0.018 \\
\pm 0.001\end{array}$ & $\begin{array}{l}0.0057 \\
\pm 0.0008\end{array}$ & $\begin{array}{l}0.009 \\
\pm 0.001\end{array}$ & $\begin{array}{l}0.015 \\
\pm 0.003\end{array}$ & $\begin{array}{l}0.0064 \\
\pm 0.0004\end{array}$ & $\begin{array}{l}0.011 \\
\pm 0.002\end{array}$ \\
\hline $\begin{array}{c}\text { Threshold Voltage } \\
V_{\text {th,sat }} \text { in V }\end{array}$ & $\begin{array}{l}0.27 \\
\pm 0.01\end{array}$ & $\begin{array}{l}-0.4 \\
\pm 0.04\end{array}$ & $\begin{array}{l}-1.89 \\
\pm 0.02\end{array}$ & $\begin{array}{l}-0.09 \\
\pm 0.02\end{array}$ & $\begin{array}{l}-0.08 \\
\pm 0.02\end{array}$ & $\begin{array}{l}-0.37 \\
\pm 0.02\end{array}$ & $\begin{array}{l}0.54 \\
\pm 0.01\end{array}$ \\
\hline $\begin{array}{c}\text { Threshold Voltage } \\
V_{\text {th,lin }} \text { in V }\end{array}$ & $\begin{array}{l}2.81 \\
\pm 0.03\end{array}$ & $\begin{array}{l}1.22 \\
\pm 0.02\end{array}$ & $\begin{array}{l}0.19 \\
\pm 0.03\end{array}$ & $\begin{array}{l}2.05 \\
\pm 0.04\end{array}$ & $\begin{array}{l}1.07 \\
\pm 0.01\end{array}$ & $\begin{array}{l}3.5 \\
\pm 0.07\end{array}$ & $\begin{array}{l}5.54 \\
\pm 0.02\end{array}$ \\
\hline
\end{tabular}




\section{REFERENCES}

(1) Vanderbilt, D. Soft Self-Consistent Pseudopotentials in a Generalized Eigenvalue Formalism. Phys. Rev. B 1990, 41, 7892.

(2) Perdew, J. P.; Burke, K.; Ernzerhof, M. Generalized Gradient Approximation Made Simple. Phys. Rev. Lett. 1996, 77, 3865-3868.

(3) Schreiber, F. Structure and Growth of Self-Assembling Monolayers. Prog. Surf. Sci. 2000, $65,151-526$.

(4) Bramblett, A. L.; S. Boeckl, M.; Hauch, K. D.; Ratner, B. D.; Sasaki, T.; Rogers, J. W. Determination of Surface Coverage for Tetraphenylporphyrin Monolayers Using Ultraviolet Visible Absorption and X-Ray Photoelectron Spectroscopies. Surf. Interface Anal. 2002, 33, 506-515.

(5) Ulman, A. Formation and Structure of Self-Assembled Monolayers. Chem. Rev. 1996, 96, 1533-1554.

(6) Laibinis, P. E.; Whitesides, G. M. Self-Assembled Monolayers of N-Alkanethiolates on Copper Are Barrier Films That Protect the Metal against Oxidation by Air. J. Am. Chem. Soc. 1992, 114, 9022-9028.

(7) Driver, S. M.; Woodruff, D. P. Scanning Tunnelling Microscopy Study of the Interaction of Dimethyl Disulphide with Cu (111). Surf. Sci. 2000, 457, 11-23.

(8) Driver, S. M.; Woodruff, D. P. Adsorption Structures of 1-Octanethiol on Cu(111) Studied by Scanning Tunneling Microscopy. Langmuir 2000, 16, 6693-6700.

(9) Hüfner, S. Photoelectron Spectroscopy; 2nd editio.; Springer Verlag: Berlin, 1995.

(10) Schulz, P.; Schäfer, T.; Zangmeister, C. D.; Effertz, C.; Meyer, D.; Mokros, D.; van Zee, R. D.; Mazzarello, R.; Wuttig, M. A New Route to Low Resistance Contacts for Performance-Enhanced Organic Electronic Devices. Adv. Mater. Interfaces 2014. 